\title{
Enhancing aesthetic appreciation by priming canvases with actions that match the artist's painting style
}

\author{
Luca F. Ticini ${ }^{1,2,3,4,5,6 *}$, Laura Rachman ${ }^{1,2,3,4}$, Jerome Pelletier ${ }^{5}$ and Stephanie Dubal ${ }^{1,2,3,4}$ \\ ${ }^{1}$ Institut du Cerveau et de la Moelle Épinière, ICM, Social and Affective Neuroscience (SAN) Laboratory, Paris, France \\ 2 Sorbonne Universités, UPMC Univ Paris 06, UMR S 1127, Paris, France \\ ${ }^{3}$ Inserm, U 1127, Paris, France \\ ${ }^{4}$ CNRS, UMR 7225, Paris, France \\ ${ }^{5}$ Institut Jean Nicod, CNRS-EHESS-ENS UMR 8129, Paris, France \\ 6 The Italian Society for Neuroaesthetics 'Semir Zeki', Trieste, Italy
}

\section{Edited by:}

Silvio lonta, University Hospital Center (CHUV) and University of Lausanne (UNIL), Switzerland

\section{Reviewed by:}

Alissa Fourkas, National Institutes of Health, USA

Luis Carlo Bulnes, Vrije Universiteit

Brussel, Belgium

*Correspondence:

Luca F. Ticini, School of

Psychological Sciences, The

University of Manchester, Zochonis

Building, Brunswick Street

Manchester M13 9PL, UK

e-mail: Iuca.ticini@gmail.com
The creation of an artwork requires motor activity. To what extent is art appreciation divorced from that activity and to what extent is it linked to it? That is the question which we set out to answer. We presented participants with pointillist-style paintings featuring discernible brushstrokes and asked them to rate their liking of each canvas when it was preceded by images priming a motor act either compatible or incompatible with the simulation of the artist's movements. We show that action priming, when congruent with the artist's painting style, enhanced aesthetic preference. These results support the hypothesis that involuntary covert painting simulation contributes to aesthetic appreciation during passive observation of artwork.

Keywords: action, priming, simulation, aesthetic appreciation, art, mirror neurons

\section{INTRODUCTION}

Perceptual, cognitive, and affective evaluations contributes to the aesthetic experience of a work of art (Cela-Conde et al., 2004; Kawabata and Zeki, 2004; Vartanian and Goel, 2004). Although much research has focused on reward-related brain regions involved in artistic preference (above all the oribitofrontal cortex; Jacobsen et al., 2006; Ishizu and Zeki, 2011, 2013; see also Ticini and Omigie, 2013), the role of other brain structures has remained thus far poorly explored. Here, we investigate the contribution of motor areas to aesthetic experience, a topic of very wide interest (Freedberg and Gallese, 2007). Several neuroimaging experiments have shown that the perception of artworks elicits motor activity in the observers' brain without fully clarifying its role in aesthetic experience (Kawabata and Zeki, 2004; Cela-Conde et al., 2009; Cross et al., 2011; Ishizu and Zeki, 2011, 2013; Cross and Ticini, 2012; Umiltà et al., 2012; Sbriscia-Fioretti et al., 2013). Indeed, on the one hand, motor activity may simply be triggered by a covert approach or avoidance response related to the emotional nature of the artwork, as it has been shown for other types of stimuli (Hajcak et al., 2007). On the other, some have hypothesized that it may represent the covert and involuntary simulation of the artist's gestures when viewing a work of art, signs of which may be present on the canvas in the form of brushstrokes (Freedberg and Gallese, 2007). Whether the latter interpretation is correct and whether motor activity contributes to the aesthetic experience at all, is still unclear.

We recorded the preference of naïve individuals for 90 high quality reproductions of pointillist-style paintings presented under conditions specifically designed either to be compatible or not with the actions required to produce them (as established in associative training conducted beforehand, see Materials and Methods). Each painting was preceded by a supraliminal priming consisting of a static image depicting a hand either holding a paintbrush with a precision (Compatible) or a power grip (Incompatible). A hand resting palm down on a table was used as baseline (Control). We hypothesized that if action simulation is causally involved in the affective response to art, subjects would like the artwork in the Compatible condition more than in the other two conditions.

\section{MATERIALS AND METHODS PARTICIPANTS}

Twenty naïve healthy right-handed individuals (13 females; mean $=24$ years) participated in the study. They were all naïve to the purpose of the investigation and with normal or correctedto-normal vision.

\section{STIMULI}

Stimuli consisted of 90 high quality color images of pointilliststyle paintings (Table 1). Thirteen individuals ( 7 females; mean age $=27.9$ years $)$ who did not participate in the study preselected them among 200 canvases according to their style: pointillist-style, stroke-style, or otherwise. 90 images indicated as pointillist-style paintings by at least 10 out of 13 subjects were chosen for the experiment. Furthermore, three right gloved-hand images (holding a paintbrush with a power or a precision grip, or rested palm down) were used in the sensorimotor training (see Visuomotor Training) and as 
Table 1 | List of the pointillist-style paintings used in the experiment.

\begin{tabular}{|c|c|c|c|c|c|}
\hline Surname & Name & Title & Surname & Name & Title \\
\hline Marevna & & Обнаженная & Signac & Paul & Pine Tree at Saint-Tropez \\
\hline Cross & Henri-Edmond & A Venetian Canal & Matisse & Henri & Le Cap Layet \\
\hline Franco & Angelo & Blooming Tree & Matisse & Henri & Luxe, Calme et Volupté \\
\hline Ferrigno & Andrea & Divide and Conquer & Matisse & Henri & Still Life \\
\hline Franco & Angelo & Abstract Forest IV & Matisse & Henri & Still Life with Purro II \\
\hline Zeniuk & Jerry & Untitled & Metzinger & Jean & Bathers, Two Nudes in an Exotic Landscape \\
\hline Dellavallée & Henri & Farmyard & Metzinger & Jean & Bord de Mer \\
\hline Dellavallée & Henri & La Rue au Soleil à Port-Manech & Metzinger & Jean & Femme Assise au Bouquet de Feuilage \\
\hline Holton & William & Garden & Metzinger & Jean & Le Château de Clisson \\
\hline Holton & William & Attractor & Metzinger & Jean & Nature Morte \\
\hline Franco & Angelo & Forest Abstraction & Metzinger & Jean & Paysage au Deux Cypres \\
\hline Franco & Angelo & Forest Abstraction \#6 & Metzinger & Jean & Paysage Neo-Impressiste \\
\hline Franco & Angelo & Forest of Love & Metzinger & Jean & Matin au Parc Montsouris \\
\hline Holton & William & Indra & Metzinger & Jean & Parc Monceau \\
\hline Franco & Angelo & Virginia Forest Abstraction 1 & Klee & Paul & Croix et Colonnes \\
\hline Franco & Angelo & Floral Abstraction Verdant & Picabia & Francis & View of St. Tropez from the Citadel \\
\hline Franco & Angelo & Manhattan Pidgeon & Picasso & Pablo & Le Retour du Bapteme, d'apres le Nain \\
\hline Franco & Angelo & November Bouquet & Pissarro & Camille & Children on a Farm \\
\hline Franco & Angelo & Nude Abstraction & Signac & Paul & Palais des Papes Avignon \\
\hline Franco & Angelo & Portrait of a Hill & Franco & Sean & Bouquet in Ochre \\
\hline Franco & Angelo & Rare Bird & Segal & Arthur & Marseille \\
\hline Angrand & Charles & In the Garden & Seurat & Georges & The Maria-Honfleur \\
\hline Angrand & Charles & Couple dans la Rue & Signac & Paul & The Port of Saint-Tropez \\
\hline Balla & Giacomo & Girl Running on a Balcony & Signac & Paul & River's Edge-the Seine at Herblay \\
\hline Cross & Henri-Edmond & The Golden Isles & Seurat & Georges & Port-en-Bessin-Avant-Port Marée Haute \\
\hline Holton & William & Fallout & Seurat & Georges & Port-en-Bessin-Entrance to the Harbor \\
\hline Cross & Henri-Edmond & Sunset on the Lagoon Venice & Signac & Paul & Les Andelys—the Riverbank \\
\hline Signac & Paul & Saint-Tropez-the Storm & Seurat & Georges & Gravelines Annonciade \\
\hline Cross & Henri-Edmond & Undergrowth & Lemmen & Georges & Factories on the Thames \\
\hline Cross & Henri-Edmond & La Chaine des Maures & Goldstein & Leonard & Going Home in Black and White \#1 \\
\hline Cross & Henri-Edmond & The Scarab & van Rysselberghe & Théo & Pointe Saint-Pierre at Saint-Tropez \\
\hline Cross & Henri-Edmond & The Wood & Goldstein & Leonard & Shield of Moie \\
\hline Cross & Henri-Edmond & Cypresses at Cagnes & Goldstein & Leonard & Flower Nebular \#2 \\
\hline Dali & Salvador & Madrid, Architecture and Poplars & Luce & Maximilien & The Seine at Herblay \\
\hline Dali & Salvador & Dawn, Noon, Sunset and Dusk & Luce & Maximilien & Montmartre-de la Rue Cortot, Vue vers Saint-Denis \\
\hline Dali & Salvador & Bathers of Llane & Luce & Maximilien & Morning Interior \\
\hline Derain & André & Boats at Collioure & van Rysselberghe & Théo & Sailboats and Estuary \\
\hline Dubois & Louis & La Marne à l'Aube & Malevich & Kazimir & Landscape \\
\hline Biggi & Gastone & Apalachi & van Dongen & Kees & Le Moulin de la Galette \\
\hline Signac & Paul & Saint-Tropez-the Storm & Marevna & & Flower Still Life \\
\hline Biggi & Gastone & Odessa Chant & Kusama & Yayoi & Sunlight \\
\hline Signac & Paul & View of Saint-Tropez & Lacombe & Georges & In the Forest \\
\hline Vuillard & Edouard & My Grandmother & Lemmen & Georges & Beach at Heist \\
\hline Biggi & Gastone & Attraversamenti & Lemmen & Georges & Heyst No.3 High Tide \\
\hline Hofmann & Hans & Self Portrait & Lemmen & Georges & View of the Thames \\
\hline
\end{tabular}

supraliminal priming images in the experiment (see Painting Observation and Liking Rates). All images were adjusted to the same size $(470 \times 351$ pixels $)$ using Adobe Photoshop and presented on a screen with a resolution of $1280 \times 800$ pixels, at $55 \mathrm{~cm}$ distance to subtend $12^{\circ}$ horizontal and $9^{\circ}$ vertical visual angles.

\section{VISUOMOTOR TRAINING}

We first established an association between the participants' own movements and the creation of pointillist-style or stroke-style paintings. To achieve this, we presented the participants with one out of three right gloved-hand images (Figure 1A) displayed on a screen (in random order, for $10 \mathrm{~s}, 6$ times each) that served as 
instruction for the subjects to perform the desired training with the right hand.

The image of the hand holding a paintbrush with a precision grip instructed the participants to paint dots by executing stippling movements while holding the paintbrush with the precision grip (Figure 1B). The image depicting the hand holding a paintbrush with a power grip instructed the participants to paint strokes of about $10 \mathrm{~cm}$ by holding the paintbrush with a power grip (Figure 1C). The image depicting the hand rested palm down instructed the participants to position their hand palm down on the table. Task completion was supervised by the experimenter. The training was repeated before the first, third and sixth primed blocks (see below) for each grip (10 s each) to strengthen the visuomotor association.

\section{PAINTING OBSERVATION AND LIKING RATES}

After the visuomotor training, participants observed the 90 pointillist-style paintings preceded by one of the three images (700-1000 ms, randomly presented) depicting a right glovedhand holding a paintbrush with a grip that supraliminally primed actions (for studies investigating how hand images prime actions see Borghi et al., 2007) that were either Compatible (precision grip) or Incompatible (power grip) with the drawing of pointillist-style paintings (Figure $2 \mathbf{A}$ ). A palm down image served as Control. Each painting was presented three times, in nine randomized blocks (of 30 trials each) preceded by a different priming image. After $500 \mathrm{~ms}$, the participants rated the paintings by moving a dot along a 9-point Likert-type scale displayed below the painting for $2500 \mathrm{~ms}$ (from "I like it very much" to "I do not like it at all," direction counterbalanced across subjects) by left ring and index finger key-presses. Choices were confirmed by

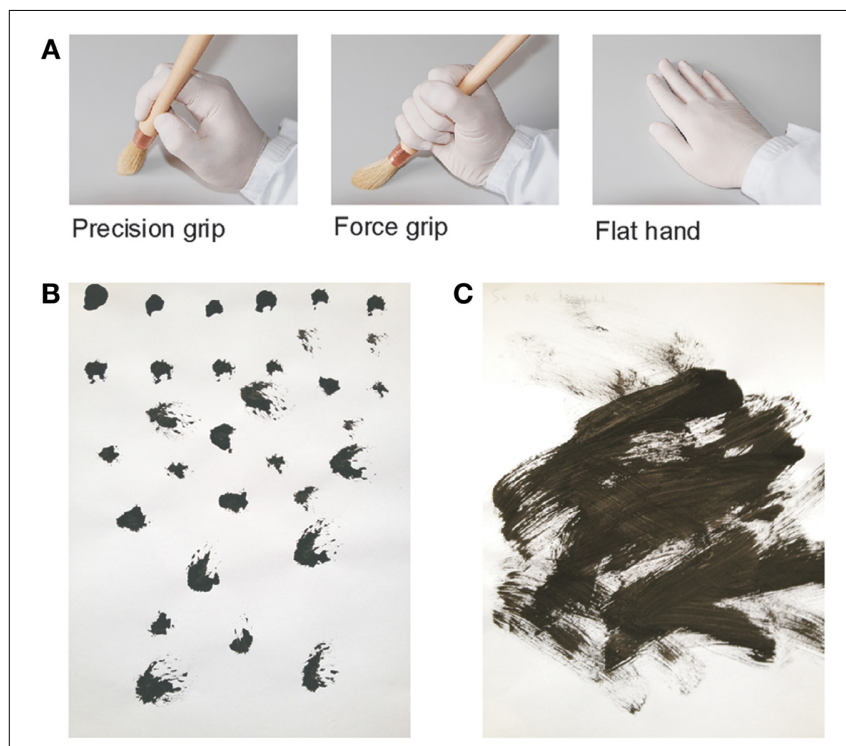

FIGURE 1 | Visuomotor training. During the associative training, three images (A) depicting a right gloved-hand holding a paintbrush with a precision or a power grip (or rested palm down as control) instructed the participants to produce pointillist-style (B), and stroke-style (C), respectively. middle finger key-presses. A $1000 \mathrm{~ms}$ blank screen completed each trial. Due to the numerous unconfirmed ratings ( $\geq 10 \%)$ two participants were excluded from further analysis. In the remaining 18 , a total of $3.25 \%$ of unconfirmed ratings was excluded.

\section{FAMILIARITY}

Upon completion of the experiment, the participants were debriefed to assess their familiarity with art by using an art questionnaire adapted from Chatterjee et al. (2010) by excluding questions 1-3 due to differences between the France and USA education systems. A median split (median of the Sums $=5.5$ ) of the questions in Table 2 separated the participants into art-familiar and art-unfamiliar groups composed of nine participants each.

\section{STATISTICAL ANALYSIS}

To asses whether covert painting simulation modulated the liking rating, we entered the ratings in a 3 (Condition: Compatible, Incompatible, Control; within subjects) $\times 2$ (Group: art-familiar, art-unfamiliar; between subjects) ANOVA. A significance threshold of $p<0.05$ was set for all statistical tests.

\section{RESULTS}

The main factor Group $\left[F_{(1,16)}=0.665, p=0.427, \eta_{p}^{2}=0.040\right]$ and the interaction Group $\times$ Condition $\left[F_{(2,32)}=2.577, p=\right.$ $\left.0.092, \eta_{p}^{2}=0.139\right]$ were not significant. In other words, this result indicates that art familiarity did not influence the results. Instead, the factor Condition was significant $\left[F_{(2,32)}=3.355, p=0.047\right.$, $\left.\eta_{p}^{2}=0.173\right]$. In particular, the aesthetic preference expressed for the paintings in the Compatible condition (4.974 \pm 0.181 ; Mean \pm s.e.m.) was significantly higher ( $p=0.048$, NewmanKeuls post-hoc test) than that in the Incompatible condition $(4.877 \pm 0.168)$, and marginally different $(p=0.067)$ from that in the Control condition ( $4.899 \pm 0.176$; Figure $2 B)$. Instead, the liking rates did not differ between the Incompatible and Control conditions $(p=0.567)$.

Correlations between each condition and individuals' sum of experience ratings (see Table 2) were not significant (Pearson correlations $r s<0.236$, $p s>0.346$ ) thus ruling out any association between familiarity and liking scores.

\section{DISCUSSION}

In this behavioral study we show that the aesthetic appreciation for pointillist-style paintings is enhanced by presenting supraliminal action priming images that are congruent (Compatible condition) with the style required to create those paintings. How can the priming modulate liking ratings of passively observed canvases? We believe that the congruent priming facilitated the covert simulation of the brushstrokes present in the paintings, thus yielding to higher ratings. This interpretation is consistent with the hypothesis that motor structures have a role in aesthetic and particularly that involuntary painting simulation contributes to aesthetic appreciation (Freedberg and Gallese, 2007; Leder et al., 2012; Umiltà et al., 2012). In agreement with previous work (Umiltà et al., 2012), our results also suggest that this effect is independent of familiarity with art. Nonetheless, since all participants were not actively engaged in creating artwork (see Question 

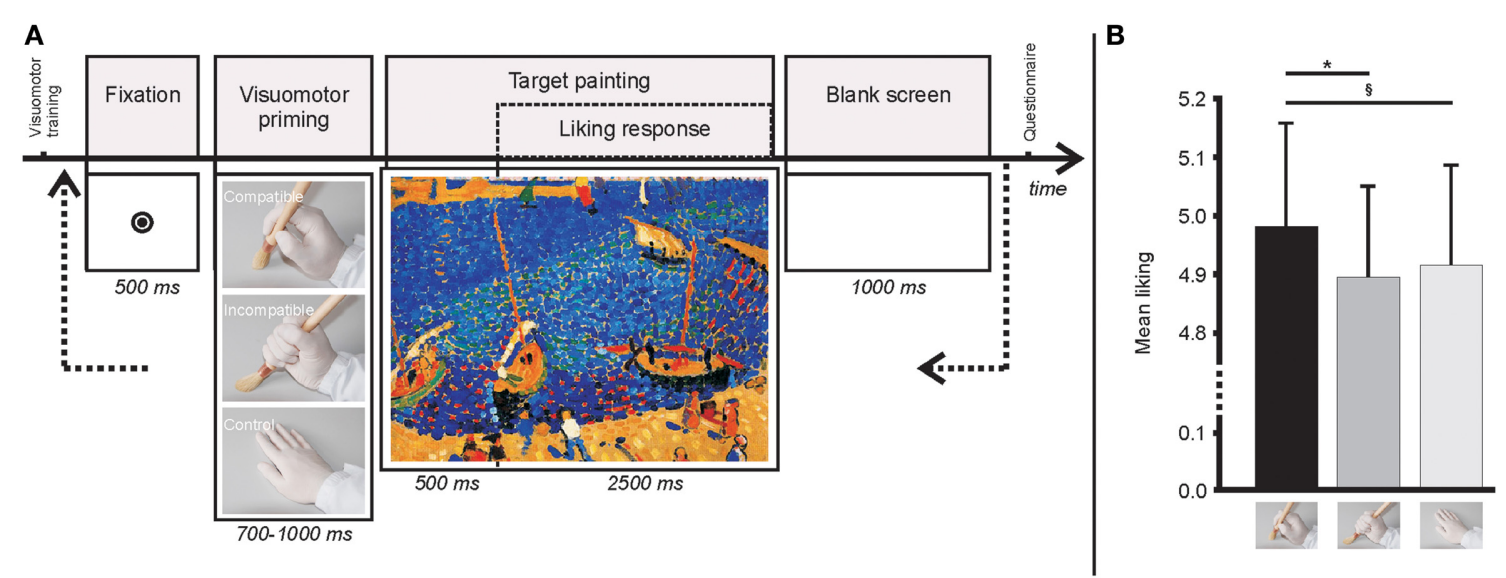

FIGURE 2 | (A) Images of a gloved-hand holding a paintbrush were used as supraliminal priming before the display of each pointillist-style painting. The images consisted of either a precision or a power grip, or of a rested palm down hand and they created three conditions. Compatible (precision grip) or Incompatible (power grip) with the drawing of pointillist-style paintings. The palm down image served as Control. (B) The preference expressed when the paintings were preceded by priming images activating motor programs Compatible with the production of pointillist-style brushstrokes was higher than that expressed for the Incompatible $(* p<0.05)$ and the Control (marginally significant ${ }^{\S} p=0.067$ ) conditions. The liking ratings in the Incompatible and Control conditions did not differ from each other $(p=0.567)$. Mean liking ratings in the three conditions are depicted (error bars represent s.e.m.).
3 in the Art familiarity questionnaire, Table 2) we cannot rule out the possibility that the results would be different for artists.

What is the mechanisms involved in simulating brushstrokes? The concept of covert action simulation has acquired a new interest with the work conducted on the mirror neuron mechanism in the non-human and human primate brain (Rizzolatti and Sinigaglia, 2010). Through this mechanism, other agents' actions are mirrored in one's own motor system thus, it is thought, helping to understand others' motor acts from "within." Action of other agents can be mirrored or covertly simulated when they are directly observed as well as when they are represented as static pictures (i.e., images depicting body movements, see Mado-Proverbio et al., 2009; Urgesi et al., 2010), and when they are hidden from view and only their sound (Ticini et al., 2012) or their traces (Longcamp et al., 2003) are perceived. For instance, there is evidence that observation of hand written letters triggers activity in motor areas involved in writings (Longcamp et al., 2003; see also Ticini, 2013), and particularly that learning to write facilitates the visual recognition of letters through the participation of brain areas known to be activated by the execution, imagery and observation of actions (Longcamp et al., 2008). Our result is supported by these and more recent behavioral findings reporting that the direction of observed brushstrokes affects participants' response speed in reaction time experiments (Taylor et al., 2012) and that active execution of movements increases (or decreases) the viewer's liking ratings when they match (or not) the style of the painting (Leder et al., 2012).

These results could be also explained by alternative mechanisms not necessarily involving painting simulation. For instance, it is plausible that the implicit knowledge about the correct action needed to manipulate the paintbrush (see Buxbaum and Kalenine, 2010) may have facilitated the most functional and effortless motor program to grasp a brush in order to create pointillist-like paintings. This would be in accordance with the idea that fluency in stimulus processing can influence aesthetic responses, as well (Reber et al., 2004). Moreover, unlike in Leder et al. (2012), we cannot exclude that self-observation of one own's hands during the training may have strengthened visuo-visual (instead of visuo-motor) associations between the hand grip and the painting style. We also cannot exclude that an intrinsic affective value of the action primes may have biased the preference ratings (e.g., the precision grip could have been perceived as more positive than the power grip). In this regard, a recent article from Flexas et al. showed differences in liking for abstract artwork when they were preceded by facial primes showing happiness, disgust or no emotion (Flexas et al., 2013). In particular, paintings preceded by happiness primes were liked more than those preceded by disgust primes. If it were the case in our experimental setup, our results would extend previous research on how the affective transfer elicited by priming may influence evaluative judgments (e.g., Murphy and Zajonc, 1993; Rotteveel et al., 2001) to the domain of aesthetic experience. Finally, we cannot exclude that the prior training alone could be sufficient to enhance the ratings as a result of an exposure effect, without the need of priming images presented before each painting.

In conclusion, we here provide empirical evidence that, beyond other factors such as upbringing, historical context and nature of the artistic stimuli, covert painting simulation may influence affective responses to art (Freedberg and Gallese, 2007). Although we cannot fully rule out alternative explanations, we suggest that the contribution of motor areas may be fundamental for the attribution of the hedonic value to some objects of art. Since simulation appears pivotal for understanding the actions and emotions of others, one important area of future research 
Table 2 | Art familiarity questionnaire.

\begin{tabular}{lccccccc}
\hline Subject & Q1 & Q2 & Q3 & Q4 & Q5 & Sum & Group \\
\hline 1 & 2 & 2 & 0 & 0 & 1 & 5 & 1 \\
2 & 4 & 4 & 0 & 0 & 0 & 8 & 2 \\
3 & 2 & 2 & 0 & 0 & 0 & 4 & 1 \\
4 & 2 & 2 & 0 & 0 & 0 & 4 & 1 \\
5 & 4 & 2 & 0 & 0 & 0 & 6 & 2 \\
6 & 4 & 4 & 0 & 0 & 0 & 8 & 2 \\
7 & 4 & 2 & 0 & 0 & 2 & 8 & 2 \\
8 & 5 & 3 & 0 & 2 & 2 & 12 & 2 \\
9 & 5 & 4 & 2 & 1 & 5 & 17 & 2 \\
10 & 2 & 1 & 0 & 0 & 1 & 4 & 1 \\
11 & 2 & 0 & 0 & 0 & 0 & 2 & 1 \\
12 & 0 & 0 & 0 & 0 & 0 & 0 & 1 \\
13 & 2 & 0 & 0 & 0 & 0 & 2 & 1 \\
14 & 0 & 0 & 0 & 0 & 0 & 0 & 1 \\
15 & 4 & 4 & 0 & 6 & 2 & 16 & 2 \\
16 & 3 & 2 & 0 & 1 & 2 & 8 & 2 \\
17 & 2 & 1 & 0 & 1 & 1 & 5 & 1 \\
18 & 4 & 4 & 0 & 1 & 1 & 10 & 2
\end{tabular}

Participants were divided into two Groups according to a questionnaire on art familiarity. Group 1 (median of the Sum < 5.5) and Group 2 (median of the Sum > 5.5) were composed of participants (nine in each group) with less or more art familiarity, respectively. Questionnaire: Q1. On average, you visit art museums about once every...( $\left(^{*}\right) ; 02$. On average, you visit art galleries about once every...( ( $\left.{ }^{*}\right)$; 03. In the average week how many hours do you spend making visual art? (range: "O" to "6 or above"); Q4. In the average week how many hours do you spend reading a publication that is related to visual art? (range: " 0 " to "6 or above"); 05. In the average week how many hours do you spend each week looking at visual art? "range for $Q 1$ and Q2: " 0 " to "5." 0 (almost never), 1 (once a year), 2 (once every 6 months), 3 (once every 2 months), 4 (once a month), 5 (once a week).

will be to characterize its influence on affective centers beyond the domain of artistic preference. Obtaining a better understanding of the contribution of action simulation in affective states is likely to shed light not just on how the brain encodes affective stimuli but also may enrich our perspective on the neural mechanisms involved in some social and communicative deficits associated with action simulation, such as autism spectrum disorder (Oberman and Ramachandran, 2007).

\section{ACKNOWLEDGMENTS}

The authors wish to thank A. Berthoz, H. Leder, M. Nadal, and the reviewers for their insightful comments. This work was supported by the French National Research Agency (ANR-10-CREA-005).

\section{REFERENCES}

Borghi, A. M., Bonfiglioli, C., Lugli, L., Ricciardelli, P., Rubichi, S., and Nicoletti, R. (2007). Are visual stimuli sufficient to evoke motor information? Studies with hand primes. Neurosci. Lett. 411, 17-21. doi: 10.1016/j.neulet.2006.10.003

Buxbaum, L. J., and Kalenine, S. (2010). Action knowledge, visuomotor activation, and embodiment in the two action systems. Ann. N.Y. Acad. Sci. 1191, 201-218. doi: 10.1111/j.1749-6632.2010.05447.x

Cela-Conde, C. J., Ayala, F. J., Munar, E., Maestú, F., Nadal, M., Capó, M. A., et al. (2009). Sex-related similarities and differences in the neural correlates of beauty. Proc. Natl. Acad. Sci. U.S.A. 106, 3847-3852. doi: 10.1073/pnas.0900 304106
Cela-Conde, C. J., Marty, G., Maestú, F., Ortiz, T., Munar, E., Fernández, A., et al. (2004). Activation of the prefrontal cortex in the human visual aesthetic perception. Proc. Natl. Acad. Sci. U.S.A. 101, 6321-6325. doi: 10.1073/pnas. 0401427101

Chatterjee, A., Widick, P., Sternschein, R., Smith, W. B., and Bromberger, B. (2010). The assessment of art attributes. Empir. Stud. Arts 28, 207-222. doi: 10.2190/EM.28.2.f

Cross, E. S., Kirsch, L., Ticini, L. F., and Schuetz-Bosbach, S. (2011). The impact of aesthetic evaluation and physical ability on dance perception. Front. Hum. Neurosci. 5:102. doi: 10.3389/fnhum.2011.00102

Cross, E. S., and Ticini, L. F. (2012). Neuroaesthetics and beyond: new horizons in applying the science of the brain to the art of dance. Phenomenol. Cogn. Sci. 11, 5-16. doi: 10.1007/s11097-010-9190-y

Flexas, A., Rosselló, J., Christensen, J. F., Nadal, M., Olivera La Rosa, A., and Munar, E. (2013). Affective priming using facial expressions modulates liking for abstract art. PLOS ONE 8:e80154. doi: 10.1371/journal.pone. 0080154

Freedberg, D., and Gallese, V. (2007). Motion, emotion and empathy in esthetic experience. Trends Cogn. Sci. 11, 197-203. doi: 10.1016/j.tics.2007. 02.003

Hajcak, G., Molnar, C., George, M. S., Bolger, K., Koola, J., and Nahas, Z. (2007). Emotion facilitates action: a transcranial magnetic stimulation study of motor cortex excitability during picture viewing. Psychophysiology 44, 91-97. doi: 10.1111/j.1469-8986.2006.00487.x

Ishizu, T., and Zeki, S. (2011). Toward a brain-based theory of beauty. PLoS ONE 6:e21852. doi: 10.1371/journal.pone.0021852

Ishizu, T., and Zeki, S. (2013). The brain's specialized systems for aesthetic and perceptual judgment. Eur. J. Neurosci. 37, 1413-1420. doi: 10.1111/ejn. 12135

Jacobsen, T., Schubotz, R. I., Höfel, L., and Cramon, D. Y. V. (2006). Brain correlates of aesthetic judgment of beauty. Neuroimage 29, 276-285. doi: 10.1016/j.neuroimage.2005.07.010

Kawabata, H., and Zeki, S. (2004). Neural correlates of beauty. J. Neurophysiol. 91, 1699-1705. doi: 10.1152/jn.00696.2003

Leder, H., Bär, S., and Topolinski, S. (2012). Covert painting simulations influence aesthetic appreciation of artworks. Psychol. Sci. 23, 1479-1481. doi: 10.1177/0956797612452866

Longcamp, M., Anton, J.-L., Roth, M., and Velay, J.-L. (2003). Visual presentation of single letters activates a premotor area involved in writing. Neuroimage 19, 1492-1500. doi: 10.1016/S1053-8119(03)00088-0

Longcamp, M., Boucard, C., Gilhodes, J.-C., Anton, J.-L., Roth, M., Nazarian, B., et al. (2008). Learning through hand- or typewriting influences visual recognition of new graphic shapes: behavioral and functional imaging evidence. J. Cogn. Neurosci. 20, 802-815. doi: 10.1162/jocn.2008. 20504

Mado-Proverbio, A. M., Riva, F., and Zani, A. (2009). Observation of static pictures of dynamic actions enhances the activity of movement-related brain areas. PLoS ONE 4:e5389. doi: 10.1371/journal.pone.0005389

Murphy, S. T., and Zajonc, R. B. (1993). Affect, cognition, and awareness: affective priming with optimal and suboptimal stimulus exposures. J. Pers. Soc. Psychol. 64, 723-739. doi: 10.1037/0022-3514.64.5.723

Oberman, L. M., and Ramachandran, V. S. (2007). The simulating social mind: the role of the mirror neuron system and simulation in the social and communicative deficits of autism spectrum disorders. Psychol. Bull. 133, 310-327. doi: 10.1037/0033-2909.133.2.310

Reber, R., Schwarz, N., and Winkielman, P. (2004). Processing fluency and aesthetic pleasure: is beauty in the perceiver's processing experience? Pers. Soc. Psychol. Rev. 8, 364-382. doi: 10.1207/s15327957 pspr0804_3

Rizzolatti, G., and Sinigaglia, C. (2010). The functional role of the parieto-frontal mirror circuit: interpretations and misinterpretations. Nat. Rev. Neurosci. 11, 264-274. doi: 10.1038/nrn2805

Rotteveel, M., de Groot, P., Geutskens, A., and Phaf, R. H. (2001). Stronger suboptimal than optimal affective priming? Emotion 1, 348-364. doi: 10.1037/15283542.1.4.348

Sbriscia-Fioretti, B., Berchio, C., Freedberg, D., Gallese, V., and Umiltà, M. A. (2013). ERP Modulation during observation of abstract paintings by Franz Kline. PLoS ONE 8:e75241. doi: 10.1371/journal.pone. 0075241 
Taylor, J. E., Witt, J. K., and Grimaldi, P. J. (2012). Uncovering the connection between artist and audience: viewing painted brushstrokes evokes corresponding action representations in the observer. Cognition 125, 26-36. doi: 10.1016/j.cognition.2012.06.012

Ticini, L. F. (2013). Does the motor cortex differentiate between linguistic symbols and scribbles? Front. Hum. Neurosci. 7:715. doi: 10.3389/fnhum.2013. 00715

Ticini, L. F., and Omigie, D. (2013). Why do we like what we like? When information flow matters. Front. Hum. Neurosci. 7:731. doi: 10.3389/fnhum.2013.00731

Ticini, L. F., Schuetz-Bosbach, S., Weiss, C., Casile, A., and Waszak, F. (2012). When sounds become actions: higher-order representation of newly learned action sounds in the human motor system. J. Cogn. Neurosci. 24, 464-474. doi: 10.1162/jocn_a_00134

Umiltà, M. A., Berchio, C., Sestito, M., Freedberg, D., and Gallese, V. (2012). Abstract art and cortical motor activation: an EEG study. Front. Hum. Neurosci. 6:311. doi: 10.3389/fnhum.2012.00311

Urgesi, C., Maieron, M., Avenanti, A., Tidoni, E., Fabbro, F., and Aglioti, S. M. (2010). Simulating the future of actions in the human corticospinal system. Cereb. Cortex 20, 2511-2521. doi: 10.1093/cercor/bhp292
Vartanian, O., and Goel, V. (2004). Neuroanatomical correlates of aesthetic preference for paintings. Neuroreport 15, 893-897. doi: 10.1097/00001756200404090-00032

Conflict of Interest Statement: The authors declare that the research was conducted in the absence of any commercial or financial relationships that could be construed as a potential conflict of interest.

Received: 16 December 2013; accepted: 16 May 2014; published online: 03 June 2014. Citation: Ticini LF, Rachman L, Pelletier J and Dubal S (2014) Enhancing aesthetic appreciation by priming canvases with actions that match the artist's painting style. Front. Hum. Neurosci. 8:391. doi: 10.3389/fnhum.2014.00391

This article was submitted to the journal Frontiers in Human Neuroscience.

Copyright (c) 2014 Ticini, Rachman, Pelletier and Dubal. This is an open-access article distributed under the terms of the Creative Commons Attribution License (CC BY).

The use, distribution or reproduction in other forums is permitted, provided the original author(s) or licensor are credited and that the original publication in this journal is cited, in accordance with accepted academic practice. No use, distribution or reproduction is permitted which does not comply with these terms. 